\title{
Molecular docking studies on DMDP derivatives as human DHFR inhibitors
}

\author{
Vivek Srivastava ${ }^{1}$, Ashutosh Kumar $^{2}$, Bhartendu Nath Mishra ${ }^{1, *}$ and Mohammad Imran Siddiqi ${ }^{2}$ \\ ${ }^{1}$ Department of Biotechnology, Institute of Engineering and Technology, Sitapur Road, Lucknow 21; ${ }^{2}$ Molecular and Structural Biology \\ Division, CDRI, Lucknow-01; Bhartendu Nath Mishra* - Email: profbnmishra@gmail.com; * Corresponding author
}

received June 18, 2008; accepted October 30, 2008; published December 06, 2008

\begin{abstract}
:
Molecular docking is routinely used for understanding drug-receptor interaction in modern drug design. Here, we describe the docking of 2, 4-diamino-5-methyl-5-deazapteridine (DMDP) derivatives as inhibitors to human dihydrofolate reductase (DHFR). We docked 78 DMDP derivates collected from literature to DHFR and studied their specific interactions with DHFR. A new shape-based method, LigandFit, was used for docking DMDP derivatives into DHFR active sites. The result indicates that the molecular docking approach is reliable and produces a good correlation coefficient $\left(\mathrm{r}^{2}=0.499\right)$ for the 73 compounds between docking score and $\mathrm{IC}_{50}$ values (Inhibitory Activity). The chloro substituted naphthyl ring of compound 63 makes significant hydrophobic contact with Leu 22, Phe 31 and Pro 61 of the DHFR active site leading to enhanced inhibition of the enzyme. The docked complexes provide better insights to design more potent DHFR inhibitors prior to their synthesis.
\end{abstract}

Keywords: DHFR inhibitors; DMDP derivatives; molecular docking; drug; receptor

\section{Background:}

Folate metabolism has long been recognized as an attractive target for cancer chemotherapy because of its indispensable role in the biosynthesis of nucleic acid precursors [1]. Within folate metabolism, Dihydrofolate reductase (DHFR) which catalyzes the reduction of folate or 7,8-dihydrofolate to tetrahydrofolate and intimately couples with thymidylate synthase has been of particular interest. The DHFR is present in all cells and is necessary for the maintenance of intracellular folate pools in a biochemically active reduced state [2]. Inhibition results in depletion of intracellular reduced folates, which are necessary for one carbon transfer reactions. One carbon transfer reactions are important for the biosynthesis of thymidylate, purine nucleotides, methionine, serine, glycine and many other compounds necessary for RNA, DNA and protein synthesis [3]. Therefore, DHFR represents an attractive target for developing antitumor agents.

Several DHFR inhibitors, as separate entities, have found clinical utility as antitumor agents [4]. The classical antifolate like methotrexate (MTX) has been used clinically for more than 50 years. Because of the frequent occurrence of tumor resistance and ineffectiveness against many solid tumors, extensive structural modifications of MTX have been reported to improve its antitumor spectrum of activity and to circumvent tumor resistance. [5] However, none of these modified analogues showed better DHFR inhibitory or antitumor activity than MTX. In addition, they require an active transport mechanism to

ISSN 0973-2063 (online) 0973-8894 (print)

Bioinformation 3(4): 180-188 (2008) enter cells, which, when impaired, causes resistance. In an attempt to overcome these potential drawbacks, non classical lipophilic antifolates have been developed as antitumor agents which do not require the folate transport system(s) and enter cells via diffusion. One such group is the derivatives of 2, 4diamino-5-methyl-5-deazapteridine (DMDP) having structures similar to the trimetrexate/piritrexim class of antifolates. Due to an interest in new anticancer drugs, several DMDP inhibitors were chosen from the Southern Research Institute chemical repository for screening against human DHFR [6].

Nowadays, molecular docking approaches are routinely used in modern drug design to help understand drug-receptor interaction. It has been shown in the literature that these computational techniques can strongly support and help the design of novel, more potent inhibitors by revealing the mechanism of drug--receptor interaction. However, so far, there has been no report concerning the application of molecular docking methodology for understanding the binding of DMDP derivatives.

In this study, we have used docking studies to study the binding orientations of DMDP derivatives to human DHFR. Such studies have been carried out to understand the forms of interaction of seventy eight compounds, synthesized by Suling and colleagues [6] for the human DHFR. The results obtained from this study would be useful in both understanding the inhibitory mode of the DMDP derivatives as well as in rapidly and accurately predicting the activities of newly designed inhibitors on the basis of docking scores. These models also 180 


\section{www.bioinformation.net}

Hypothesis

provide some beneficial clues in structural modification for designing new inhibitors for the treatment of cancer with much higher inhibitory activities against DHFR.

\section{Methodology: \\ Molecular structures and optimization}

The biological activity data of DMDP derivatives (Seventy Eight molecules), reported by Suling and colleagues [6] was used in the present study (Table 1 under supplementary material). The structures of all the compounds were constructed using the InsightII 2000.1 Builder module (http://www.accelrys.com). The geometries of these compounds were subsequently optimized using Discover module of InsightII 2000.1 using CVFF force field. The structure of human DHFR protein (PDBid code 1KMS) was obtained from Protein Data Bank.

\section{Molecular docking}

Molecular docking of DMDP derivatives to the active site of human DHFR was carried out using modern docking engine LigandFit available with Cerius2_4.9. (http://www.accelrys.com). This algorithm makes use of a cavity detection algorithm for detecting invaginations in the protein as potential active site regions. A shape comparison filter is combined with a Monte Carlo conformational search for generating ligand poses consistent with the active site shape. Candidate poses are minimized in the context of the active site using a gridbased method for evaluating protein-ligand interaction energies. The docking was carried out with the following non default settings in LigandFit: site partitioning in order to fully access the potential docking orientation of the active site, maximum trials variable table values to help the pseudorandom conformational analysis, and the CFF force field [8] option was used for the grid energy calculations. The flexible fitting option was selected for generation of alternative conformations on the fly, as was the diverse conformer's option to ensure the solutions generated covers a broad range of conformations with similar low-energy docking scores, and a maximum of 30 top scoring diverse ligand poses were returned for each of the compounds.

\section{Scoring function}

The docked conformations were further scored using various scoring functions available with Cerius2 [8]. The LigandFit algorithm [7] uses an internal scoring function, DockScore, to select and return dissimilar poses for each compound. DockScore is a simple force field based scoring function which estimates the energy of interaction by summing the ligand/protein interaction energy and the internal energy of the ligand. CFF force field [8] was used to resolve the van der Waals parameters for DockScore. The top DockScore pose was used for post docking scoring. The scoring was performed using a set of scoring functions as implemented in Cerius2 [8]. These included LigScore1, LigScore2, -PLP1, -PLP2, -PMF and

ISSN 0973-2063 (online) 0973-8894 (print)

Bioinformation 3(4): 180-188 (2008)
DockScore available from the docking process. The putative 3D poses and score results were then stored as a SD file. Each docking was minimized, using DockScore, the only purely molecular mechanics based scoring function employed in this study, and this minimized pose was then presented to each of the other scoring functions, which were either knowledge based or regression based.

\section{Protein preparation}

The high-resolution (1.09 $\AA^{\prime}$ X-ray structure of human DHFR complex with SRI 9439 (PDBid code 1KMS) was imported into Cerius2 [8], and the ligand was extracted to leave a cavity. Thereafter, the docking simulations were carried out with and without cofactor NADPH and water molecules, to elucidate the role of NADPH and water molecules for the binding of DMDP derivatives.

\section{Hardware and software}

InsightII 2000.1 (http://www.accelrys.com) and Cerius2 [8] were used for molecular modeling on a SGI Origin 300 workstation equipped with $4 * 600 \mathrm{MHz}$ R12000 processor.

\section{Results and discussion:}

To date, several crystal structure of human DHFR in complex with different inhibitors have been reported viz $1 \mathrm{DHF}$ with folate [9], $1 \mathrm{KMV}$ with NADPH and (Z)- 6-(2-[2,5Dimethoxyphenyl] Ethen-1-yl)-2,4-Diamino-5- methylpyrido [2,3-D] Pyrimidine (SRI-9662), a lipophilic antifolate [3], $1 \mathrm{KMS}$ with NADPH and 6-([5-quinolylamino]methyl)-2,4diamino-5-methylpyrido [2,3-d]pyrimidine (SRI-9439), a lipophilic antifolate [3], 1DLS with methotrexate [10] and 2DHF with 5-deazafolate [9] etc. which provide information about the exact location and composition of inhibitor binding pocket and opportunity to use the enzyme in a functional conformation. We used X-ray structure of human DHFR in complex with SRI- 9439 and NADPH (PDBid code 1KMS) for the docking study.

\section{Validation of the docking method}

To ensure that the ligand orientation obtained from the docking studies were likely to represent valid and reasonable binding modes of the inhibitors, the LigandFit program docking parameters had to be first validated for the crystal structure (PDBid 1KMS). The ligand SRI-9439, in the conformation found in the crystal structure, was extracted and docked back to the corresponding binding pocket, to determine the ability of LigandFit to reproduce the orientation and position of the inhibitor observed in the crystal structure. Results of control docking showed that LigandFit determined the optimal orientation of the docked inhibitor, SRI-9439 to be close to that of the original orientation found in the crystal shown in Figure 1 a.

The low RMS deviation of $0.502 \AA$ between the docked and crystal ligand coordinates indicate very good alignment of the experimental and calculated positions especially considering the resolution of the crystal structure (1.09 $\AA$ ).

181 


\section{Interaction Modes between the DMDP derivatives and human DHFR}

The binding modes of DMDP derivatives in the binding site of human DHFR were identified using intermolecular flexible docking simulations by means of LigandFit program. All the compounds in the dataset were docked into the active site of human DHFR, using the same protocol.

Figure $1 \mathrm{~b}$ depicts the binding conformations of the DMDP derivatives in the binding pocket of the DHFR. The active site of DHFR comprises of mostly hydrophobic amino acids as Ile7, Val8, Trp24, Phe31, Phe34, Pro61, Val115 and these amino acid residues are involved in strong hydrophobic interactions with the DMDP derivatives. As expected, inhibitors used in this study bind to the same site like the docked ligand in the crystallographic complex. The inhibitors bind in a hydrophobic pocket adjacent to helix $\alpha \mathrm{B}$, with the 5-deazapteridine ring almost perpendicular to the 5-quinolylamino group. The 5-deazapteridine ring of the inhibitors forms hydrophobic contacts with Val8, Ile7 and Phe31. The 5-deazapteridine rings of DMDP derivatives therefore bind to the human DHFR active site in an identical fashion, as reported in case of other inhibitors like methotrexate [10], SRI-9439 [3], SRI-9662 [3] etc. The DMDP derivatives bind to human DHFR mainly using the pterin moiety. As originally observed for methotrexate [10] and subsequently above inhibitors, DMDP derivatives bind with their 5deazapteridine rings flipped approximately $180^{\circ}$ along the ring long axis relative to the position of folate in the active site. Thus, the opposite side of the pteridine ring is presented to the NADPH cofactor. The N1 and N2 nitrogen atoms of the 5deazapteridine rings form hydrogen bonds (shown in Figure 1 as dotted lines) to oxygen atoms OE1 and OE2 of the side-chain of Glu30, which is highly conserved in the active site of all vertebral DHFRs $[3, \mathbf{9}, \mathbf{1 0}]$.

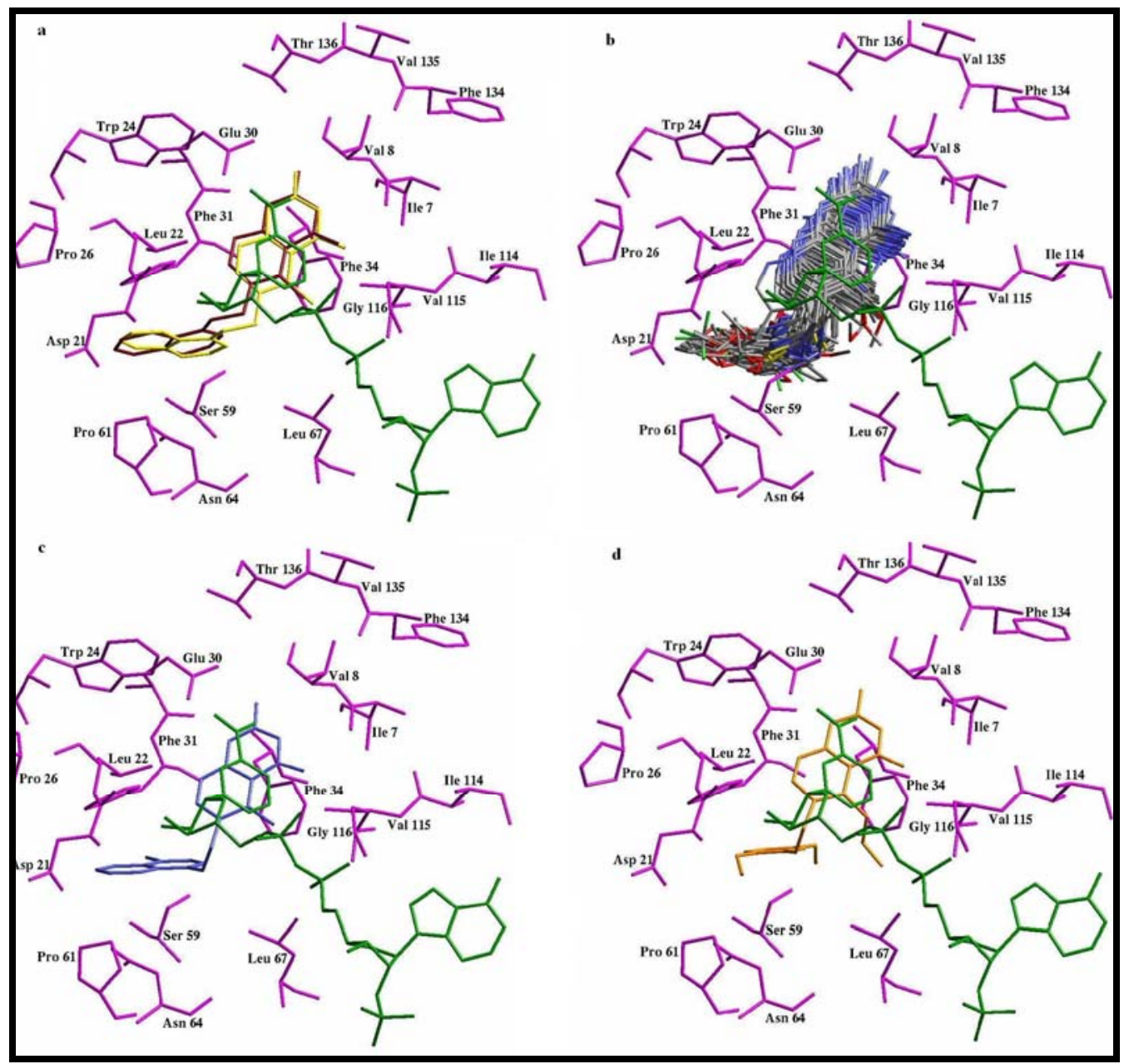

Figure 1: (a) Conformation of SRI-9439 crystal structure (red) as compared to the docked conformation of SRI-9439 (Yellow) with cofactor NADPH (green). Amino acid residues are presented in magenta, (b) The docked 3-D structures of DMDP derivatives, (c) Docked Confirmation of Compound 63 and (d) Docked Confirmation of Compound 29.

ISSN 0973-2063 (online) 0973-8894 (print) 
The binding mode of the most active compound 63 has been shown in Figure 1c. As expected, compound 63 bind to the DHFR active site in the similar conformation as other known DHFR inhibitors (SRI-9662, SRI-9439, methotrexate) which mainly bind using the pterin moiety and this moiety is presented to nicotinamide ring of cofactor NADPH. This pterin ring is involved in $\pi-\pi$ stacking interactions with the nicotinamide ring of NADPH. This stacking interaction is very important and has been conserved in most of the DHFR's for which crystal structures have been solved with NADPH and inhibitors in ternary complex with the enzyme. The chloro substituted naphthyl ring of compound 63 makes significant hydrophobic contact with Leu 22, Phe 31 and Pro 61 of the DHFR active site leading to enhanced inhibition of the enzyme when compared with compound 29 (least active) where chloro substituted naphthyl ring is substituted with phenyl ring with methoxy substitution at 2 and 5 positions leading to decreased hydrophobicity of the compound and hence low amount of inhibition as shown in Figure 1d. The two amino group of the pterin ring makes strong hydrogen bond with main chain oxygen atom of Ile 7 and Val 115 and side chain oxygen atom of Glu 30. These particular interactions play a very important role in DHFR inhibition and need to be present for good inhibition by the inhibitors. Moreover, any bulkier substitution at R1 position of the DMDP derivatives may lead to steric clashes with Phe 34 and the cofactor NADPH and that is why compound $29,45,50,51$ are not very much active, whereas compounds with methyl substitution are more active as in case of compound 63, is shown in Figure 1c.

\section{Correlation between docking scores and inhibitory} activity
The predicted inhibitory activity of DMDP derivatives as inhibitors on the basis of dock score is listed in Table 1 (supplementary material). Linear regression analysis was performed to explore whether the docking scores could be correlated with the experimental activities. The equation was obtained for the inhibitory activities represented as $\mathrm{pIC}_{50}$ values, using the Dock score, Ligscore1, Ligscore2, -PLP1, PLP2, -PMF and Consensus score as the variable descriptors. A model with the correlation coefficient $\left(r^{2}\right)$ of 0.356 was obtained for 78 compounds using the Equation 1 under supplementary material.

Removal of 5 compounds [Comp 29, Comp 32, Comp 46, Comp 48, and Comp 49] identified as outliers from the docking dataset yield a better model with correlation coefficient $\left(r^{2}\right)$ of 0.499 was obtained for 73 compounds. This rather good correlation demonstrates that the binding conformations and binding models of the DMDP derivatives with human DHFR are reasonable shown in Figure 2. Activity can be best explained for rest of the compounds using the Equation given in supplementary material.

\section{Conclusion:}

In this work, molecular docking studies were carried out to explore the binding mechanism of DMDP derivatives to the human DHFR enzyme to enable the design of new DMDPbased human DHFR inhibitors. Both the binding conformation of DMDP and their binding free energies were predicted by molecular docking. The binding free energies of these compounds to human DHFR were found to have a good correlation with the experimental inhibitory activities. The results provide insight into the structural requirement for the activity of this class inhibitor and the most favorable binding mode of the top - ranking compounds will be useful in designing new DMDP derivatives as human DHFR inhibitors.

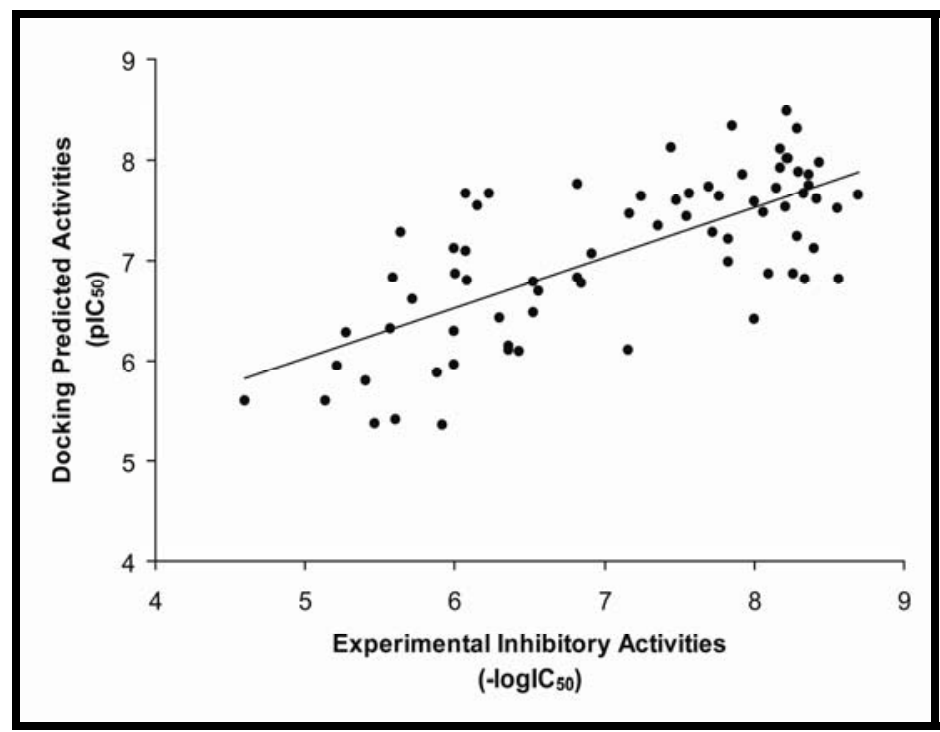

Figure 2: A correlation for binding conformations and binding models of the DMDP derivatives with human DHFR. 


\section{www.bioinformation.net}

\section{Hypothesis}

\section{Acknowledgment:}

We acknowledge to Council of Scientific and Industrial Research (CSIR), New Delhi, for financial support as a SRF (Biotechnology) at Institute of Engineering and Technology, UP Technical University (UPTU), Lucknow, India.

\section{References:}

[01] E. M. Berman and L. M. Werbel, J. Med. Chem., 34 : 479 (1991) [PMID: 1995868]

[02] J. T. Bolin et al., J. Biol. Chem., 257: 13650 (1982) [PMID: 6815178]
[03] A. E. Klon et al., J.Mol.Biol., $320: 677$ (2002) [PMID: 12096917]

[04] C. H. Takimoto, Semin. Oncol., 24: S18 (1997)

[05] A. Gangjee et al., Curr. Pharm. Des., 2: 263. (1996)

[06] W. J. Suling et al., Antimicrobial Agents and Chemotherapy, 44 : 2784 (2000) [PMID: 10991861]

[07] C. M. Venkatachalam et al., J. Mol. Graph. Model, 21 : 289 (2003) [PMID: 12479928]

[08] http://www.accelrys.com

[09] J. F. Davies et al., Biochemistry, 29 : 9467 (1990) [PMID: 2248959]

[10] W. S. Lewis et al., J.Biol.Chem., $270: 5057$ (1995) [PMID:7890613]

Edited by $P$. Kangueane

Citation: Srivastava et al., Bioinformation 3(4): 180-188 (2008)

License statement: This is an open-access article, which permits unrestricted use, distribution, and reproduction in any medium, for non-commercial purposes, provided the original author and source are credited.

\section{Supplementary material}

\section{Equations}

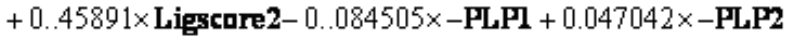

$$
\begin{aligned}
& +0.024722 \times-\mathrm{PMF}+0.0028444 \times \text { LLDI } \\
& -0.303363 \times \text { Cons_Scare }
\end{aligned}
$$

$\rightarrow \quad(1)$

$\rightarrow \quad(2)$

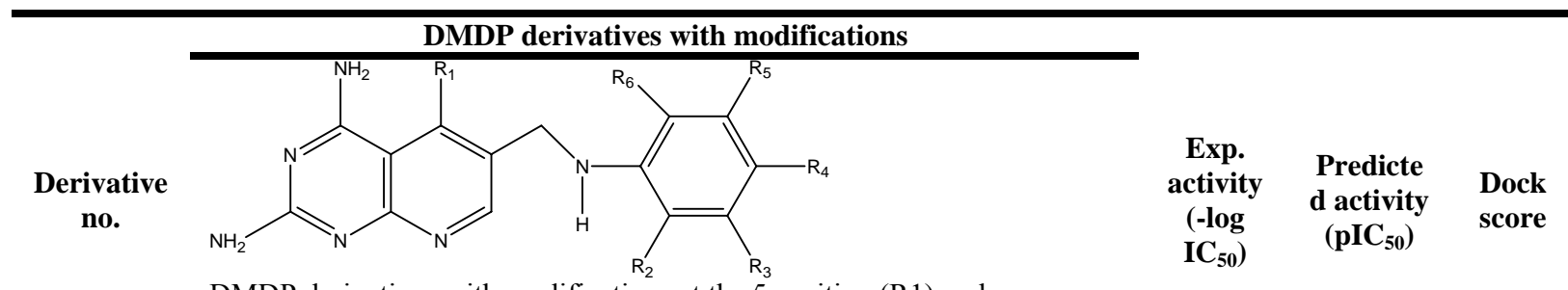

\begin{tabular}{|c|c|c|c|c|c|c|c|c|c|}
\hline & R1 & $\mathbf{R} 2$ & R3 & R4 & R5 & R6 & & & \\
\hline Comp. 1 & $-\mathrm{CH}_{3}$ & $-\mathrm{OCH}_{2} \mathrm{CH}_{3}$ & $-\mathrm{H}$ & $-\mathrm{H}$ & $-\mathrm{OCH}_{2} \mathrm{CH}_{3}$ & $-\mathrm{H}$ & 5.638 & 7.286 & 66.403 \\
\hline Comp. 2 & $-\mathrm{CH}_{3}$ & $-\mathrm{OCH}_{3}$ & $-\mathrm{H}$ & $-\mathrm{H}$ & $-\mathrm{OCH}_{3}$ & $-\mathrm{H}$ & 6.000 & 7.124 & 71.728 \\
\hline Comp. 3 & $-\mathrm{CH}_{3}$ & $-\mathrm{OCH}_{3} \mathrm{CH}_{3}$ & $-\mathrm{H}$ & $-\mathrm{H}$ & $-\mathrm{OCH}_{2} \mathrm{CH}_{3}$ & $-\mathrm{H}$ & 6.00 & 6.292 & 58.726 \\
\hline Comp. 4 & $-\mathrm{CH}_{3}$ & $-\mathrm{CH}_{3}$ & $-\mathrm{H}$ & $-\mathrm{H}$ & $-\mathrm{OCH}_{3}$ & $-\mathrm{H}$ & 6.824 & 6.823 & 64.241 \\
\hline Comp. 5 & $-\mathrm{CH}_{3}$ & $-\mathrm{CH}_{3}$ & $-\mathrm{H}$ & $-\mathrm{Br}$ & $-\mathrm{H}$ & $-\mathrm{CH}_{3}$ & 5.721 & 6.620 & 59.402 \\
\hline Comp. 6 & $-\mathrm{CH}_{2} \mathrm{CH}_{3}$ & $-\mathrm{OCH}_{3}$ & $-\mathrm{H}$ & $-\mathrm{H}$ & $-\mathrm{OCH}_{3}$ & $-\mathrm{H}$ & 6.000 & 6.071 & 63.456 \\
\hline
\end{tabular}

DMDP derivatives with modifications at the 5 position (R1) and substitutions on the phenyl group (R2 through R6). 


\section{www.bioinformation.net}

Hypothesis

\begin{tabular}{|c|c|c|c|c|c|c|c|c|c|}
\hline Comp. 7 & $-\mathrm{CH}_{3}$ & $-\mathrm{OCH}_{3}$ & $-\mathrm{H}$ & $-\mathrm{H}$ & $-\mathrm{CH}_{3}$ & $-\mathrm{H}$ & 6.523 & 6.476 & 62.092 \\
\hline Comp. 8 & $-\mathrm{CH}_{3}$ & $-\mathrm{OCHF}_{2}$ & $-\mathrm{H}$ & $-\mathrm{H}$ & $-\mathrm{H}$ & $-\mathrm{H}$ & 6.558 & 6.694 & 64.709 \\
\hline Comp. 9 & $-\mathrm{CH}_{3}$ & $-F$ & $-\mathrm{H}$ & $-\mathrm{H}$ & $-\mathrm{CH}_{3}$ & $-\mathrm{H}$ & 6.602 & 7.773 & 60.858 \\
\hline Comp. 10 & $-\mathrm{CH}_{3}$ & $-\mathrm{Cl}$ & $-\mathrm{H}$ & $-\mathrm{CH}_{3}$ & $-\mathrm{H}$ & $-\mathrm{CH}_{3}$ & 6.071 & 7.661 & 63.186 \\
\hline Comp. 11 & $-\mathrm{CH} 3$ & $-\mathrm{Cl}$ & $-\mathrm{H}$ & $-\mathrm{H}$ & $-\mathrm{H}$ & $-\mathrm{H}$ & 6.921 & 7.069 & 60.561 \\
\hline Comp. 12 & $-\mathrm{CH}_{2} \mathrm{CH}_{3}$ & $-\mathrm{OCH}_{3}$ & $-\mathrm{H}$ & $-\mathrm{H}$ & $-\mathrm{CH}_{3}$ & $-\mathrm{H}$ & 6.432 & 6.093 & 60.749 \\
\hline Comp. 13 & $-\mathrm{CH}_{3}$ & $-F$ & $-\mathrm{H}$ & $-\mathrm{H}$ & $-F$ & $-\mathrm{H}$ & 7.161 & 6.105 & 57.057 \\
\hline Comp. 14 & $-\mathrm{CH}_{3}$ & $-\mathrm{OCH}_{3}$ & $-\mathrm{H}$ & $-\mathrm{C}_{6} \mathrm{H}_{5}$ & $-\mathrm{H}$ & $-\mathrm{H}$ & 7.167 & 7.470 & 71.621 \\
\hline Comp. 15 & $-\mathrm{CH}_{3}$ & $-\mathrm{CH}_{3}$ & $-\mathrm{H}$ & $-\mathrm{H}$ & $-\mathrm{CH}_{3}$ & $-\mathrm{H}$ & 7.244 & 7.635 & 64.671 \\
\hline Comp. 16 & $-\mathrm{CH}_{3}$ & $-\mathrm{Cl}$ & $-\mathrm{H}$ & $-\mathrm{H}$ & $-\mathrm{CH}_{3}$ & $-\mathrm{H}$ & 7.357 & 7.341 & 63.469 \\
\hline Comp. 17 & $-\mathrm{CH} 3$ & $-\mathrm{Cl}$ & $-\mathrm{H}$ & $-F$ & $-\mathrm{CH}_{3}$ & $-\mathrm{H}$ & 7.481 & 7.595 & 61.363 \\
\hline Comp. 18 & $-\mathrm{CH}_{3}$ & $-\mathrm{H}$ & $-\mathrm{H}$ & $-\mathrm{Cl}$ & $-\mathrm{H}$ & $-\mathrm{H}$ & 7.569 & 7.663 & 63.152 \\
\hline Comp. 19 & $-\mathrm{CH}_{3}$ & $-\mathrm{OCH}_{3}$ & $-\mathrm{H}$ & $-\mathrm{H}$ & $-\mathrm{CF}_{3}$ & $-\mathrm{H}$ & 7.444 & 8.122 & 62.530 \\
\hline Comp. 20 & $-\mathrm{CH}_{3}$ & $-\mathrm{H}$ & $-\mathrm{OCH}_{3}$ & $-\mathrm{H}$ & $-\mathrm{OCH}_{3}$ & $-\mathrm{H}$ & 7.824 & 7.218 & 69.492 \\
\hline Comp. 21 & $-\mathrm{CH}_{3}$ & $-\mathrm{CH}_{3}$ & $-\mathrm{H}$ & $-\mathrm{H}$ & $-F$ & $-\mathrm{H}$ & 7.721 & 7.281 & 63.786 \\
\hline Comp. 22 & $-\mathrm{CH} 3$ & $-\mathrm{H}$ & $-\mathrm{Cl}$ & $-\mathrm{H}$ & $-\mathrm{H}$ & $-\mathrm{H}$ & 7.77 & 7.637 & 62.575 \\
\hline Comp. 23 & $-\mathrm{CH}_{3}$ & $-\mathrm{H}$ & $-\mathrm{H}$ & $\begin{array}{c}\text { OCHF } \\
3\end{array}$ & $-\mathrm{H}$ & $-\mathrm{H}$ & 7.699 & 7.734 & 64.907 \\
\hline Comp. 24 & $-\mathrm{CH}_{3}$ & $-\mathrm{H}$ & $-\mathrm{OCH}_{3}$ & $\begin{array}{l}\mathrm{OCH}_{3} \\
\mathrm{CH}_{3}\end{array}$ & $-\mathrm{H}$ & $-\mathrm{H}$ & 7.553 & 7.434 & 69.597 \\
\hline Comp. 25 & $-\mathrm{CH}_{3}$ & $-\mathrm{H}$ & $-\mathrm{OCH}_{3}$ & $\begin{array}{l}\mathrm{O}\left(\overline{\mathrm{CH}} \mathrm{H}_{3}\right. \\
)_{3} \mathrm{CH}_{3}\end{array}$ & $-\mathrm{H}$ & $-\mathrm{H}$ & 7.824 & 6.985 & 57.316 \\
\hline Comp. 26 & $-\mathrm{H}$ & $-\mathrm{H}$ & $-\mathrm{OCH}_{3}$ & $-\mathrm{OCH}_{3}$ & $-\mathrm{OCH}_{3}$ & $-\mathrm{H}$ & 5.409 & 5.802 & 59.546 \\
\hline Comp. 27 & $-\mathrm{CH}_{3}$ & $-\mathrm{H}$ & $-F$ & $-\mathrm{OCH}_{3}$ & $-\mathrm{H}$ & $-\mathrm{H}$ & 7.854 & 8.330 & 63.815 \\
\hline Comp. 28 & $-\mathrm{CH}_{3}$ & $-\mathrm{CH}_{3}$ & $-\mathrm{H}$ & $-\mathrm{Cl}$ & $-\mathrm{H}$ & $-\mathrm{H}$ & 8.553 & 7.522 & 63.298 \\
\hline Comp. 29 & $\underset{3}{\mathrm{CH}_{2} \mathrm{OCH}}$ & $-\mathrm{OCH}_{3}$ & $-H$ & $-H$ & $-\mathrm{OCH}_{3}$ & $-H$ & 4.509 & $*$ & $*$ \\
\hline Comp. 30 & $-\mathrm{CH}_{3}$ & $-\mathrm{H}$ & $-\mathrm{OCH}_{3}$ & $-\mathrm{H}$ & $-\mathrm{OCH}_{3}$ & $-\mathrm{H}$ & 8.060 & 7.485 & 68.155 \\
\hline Comp. 31 & $-\mathrm{CH}_{3}$ & $-\mathrm{OCH}_{3}$ & $-\mathrm{H}$ & $-\mathrm{Cl}$ & $-\mathrm{CH}_{3}$ & $-\mathrm{H}$ & 8.000 & 6.413 & 63.266 \\
\hline Comp. 32 & $-\mathbf{H}$ & $-\mathbf{H}$ & $-\mathbf{H}$ & $-\mathrm{Cl}$ & $-\mathbf{H}$ & $-\mathbf{H}$ & 6.174 & $*$ & $*$ \\
\hline Comp. 33 & $-\mathrm{CH}_{3}$ & $-\mathrm{Cl}$ & $-\mathrm{H}$ & $-\mathrm{H}$ & $-\mathrm{Cl}$ & $-\mathrm{H}$ & 8.097 & 6.872 & 64.982 \\
\hline Comp. 34 & $-\mathrm{CH}_{3}$ & $-\mathrm{CH}_{3}$ & $-\mathrm{H}$ & $-\mathrm{H}$ & $-\mathrm{Cl}$ & $-\mathrm{H}$ & 8.215 & 8.007 & 67.787 \\
\hline Comp. 35 & $-\mathrm{CH}_{3}$ & $-\mathrm{H}$ & $-\mathrm{Cl}$ & $-\mathrm{CH}_{3}$ & $-\mathrm{H}$ & $-\mathrm{H}$ & 8.174 & 8.105 & 57.504 \\
\hline Comp. 36 & $-\mathrm{CH}_{3}$ & $-\mathrm{H}$ & $-\mathrm{OCH}_{3}$ & $-\mathrm{OCH}_{3}$ & $-\mathrm{H}$ & $-\mathrm{H}$ & 8.292 & 8.307 & 69.990 \\
\hline Comp. 37 & $-\mathrm{CH} 3$ & $-\mathrm{H}$ & $-\mathrm{CH}_{3}$ & $-B r$ & $-\mathrm{H}$ & $-\mathrm{H}$ & 8.215 & 8.478 & 59.323 \\
\hline Comp. 38 & $-\mathrm{CH}_{3}$ & $-\mathrm{CH}_{3}$ & $-\mathrm{H}$ & $-B r$ & $-\mathrm{H}$ & $-\mathrm{H}$ & 8.229 & 8.009 & 61.589 \\
\hline Comp. 39 & $-\mathrm{CH}_{3}$ & $-\mathrm{Br}$ & $-\mathrm{H}$ & $-\mathrm{H}$ & $-B r$ & $-\mathrm{H}$ & 8.337 & 6.811 & 63.024 \\
\hline Comp. 40 & $-\mathrm{CH}_{3}$ & $-\mathrm{CH}_{3}$ & $-\mathrm{Cl}$ & $-\mathrm{H}$ & $-\mathrm{H}$ & $-\mathrm{H}$ & 8.284 & 7.243 & 63.173 \\
\hline Comp. 41 & $-\mathrm{CH}_{3}$ & $-\mathrm{H}$ & $-\mathrm{Br}$ & $-\mathrm{CH}_{3}$ & $-\mathrm{H}$ & $-\mathrm{H}$ & 8.432 & 7.974 & 63.701 \\
\hline Comp. 42 & $-\mathrm{CH} 3$ & $-\mathrm{H}$ & $-\mathrm{OCH}_{3}$ & $-\mathrm{H}$ & $-\mathrm{CF}_{3}$ & $-\mathrm{H}$ & 8.260 & 6.870 & 64.843 \\
\hline Comp. 43 & $-\mathrm{CH}_{3}$ & $-\mathrm{H}$ & $-\mathrm{OCH}_{3}$ & $-\mathrm{OCH}_{3}$ & $-\mathrm{OCH}_{3}$ & $-\mathrm{H}$ & 8.328 & 7.667 & 51.788 \\
\hline Comp. 44 & $-\mathrm{CH}_{3}$ & $-\mathrm{H}$ & $-\mathrm{Cl}$ & $-\mathrm{Cl}$ & $-\mathrm{H}$ & $-\mathrm{H}$ & 8.301 & 7.882 & 66.091 \\
\hline Comp. 45 & $\mathrm{CH}_{2} \mathrm{OCH}_{3}$ & $-\mathrm{H}$ & $-\mathrm{OCH}_{3}$ & $-\mathrm{OCH}_{3}$ & $-\mathrm{H}$ & $-\mathrm{H}$ & 5.215 & 5.942 & 49.975 \\
\hline Comp. 46 & $-\mathrm{CH}_{3}$ & $-\mathbf{F}$ & $-\mathbf{H}$ & $-\mathbf{H}$ & $-\mathbf{C F}_{3}$ & $-\mathbf{H}$ & 8.387 & * & * \\
\hline Comp. 47 & $-\mathrm{CH}_{3}$ & $-\mathrm{OCH}_{3}$ & $-\mathrm{H}$ & $-\mathrm{H}$ & $-\mathrm{CF}_{3}$ & $-\mathrm{H}$ & 8.569 & 6.810 & 64.199 \\
\hline Comp. 48 & $-\mathrm{CH}_{2} \mathrm{CH}_{3}$ & $-\mathrm{OCH}_{3}$ & $-\mathbf{H}$ & $-\mathbf{H}$ & $-\mathbf{C F}_{3}$ & $-\mathbf{H}$ & 8.444 & * & * \\
\hline Comp. 49 & $-\mathrm{CH}_{3}$ & $-\mathrm{Br}$ & $-\mathbf{H}$ & $-\mathbf{H}$ & $-\mathbf{C F}_{3}$ & $-\mathbf{H}$ & 8.495 & $*$ & $*$ \\
\hline Comp. 50 & $\mathrm{CH}_{2} \mathrm{OCCH}_{3}$ & $-\mathrm{H}$ & $-\mathrm{OCH}_{3}$ & $-\mathrm{OCH}_{3}$ & $-\mathrm{OCH}_{3}$ & $-\mathrm{H}$ & 5.886 & 5.878 & 49.447 \\
\hline
\end{tabular}




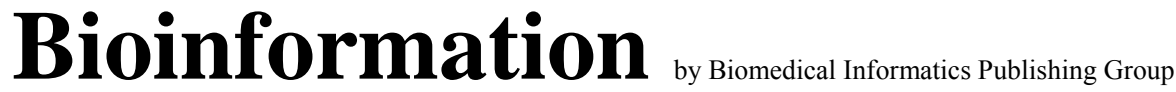

\section{www.bioinformation.net}

\section{Hypothesis}

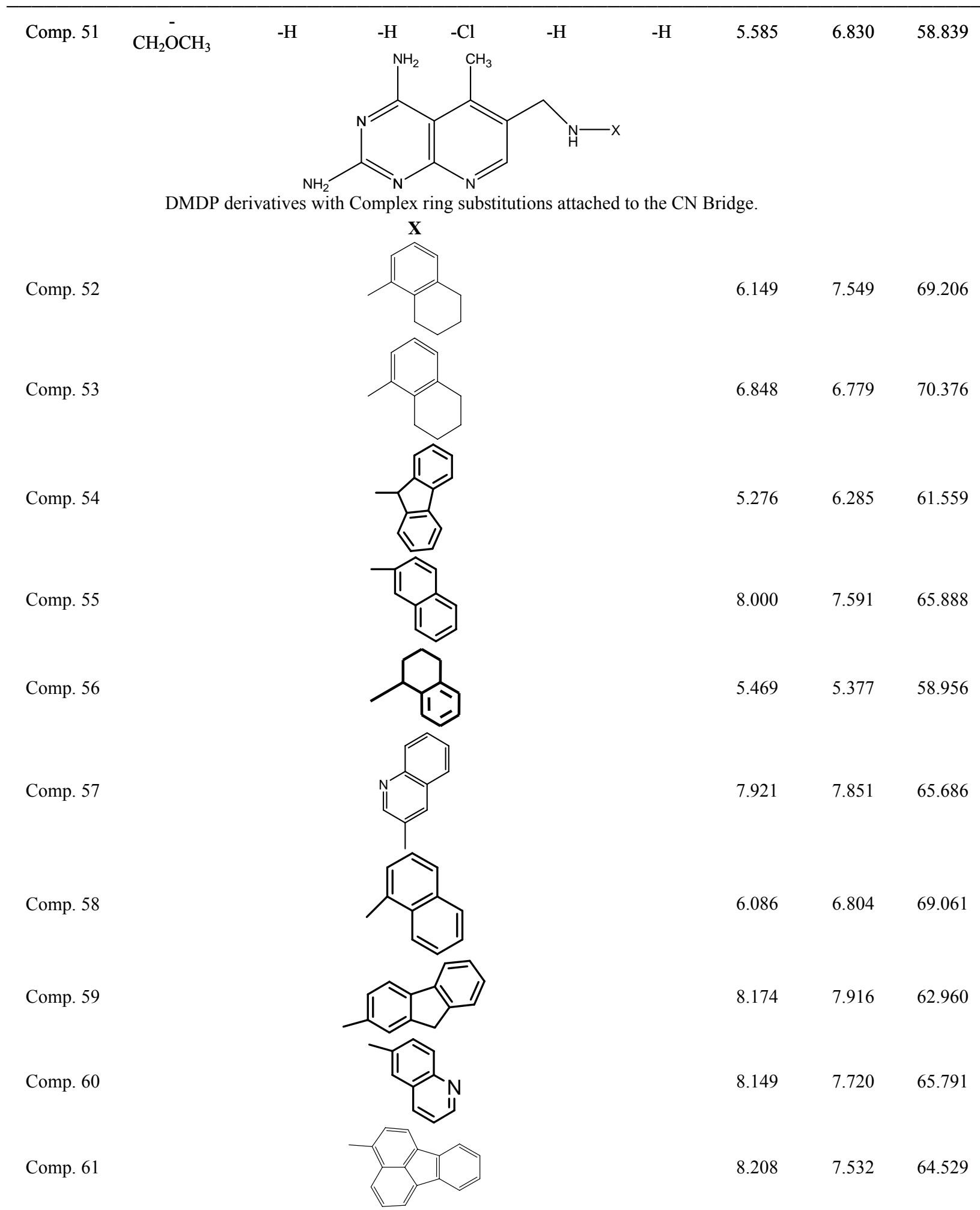




\begin{tabular}{|c|c|c|c|c|c|c|c|c|c|}
\hline Comp. 62 & & & & & & & 8.367 & 7.850 & 61.467 \\
\hline Comp. 63 & & & & & & & 8.699 & 7.649 & 67.200 \\
\hline Comp. 64 & & & & & & & 8.398 & 7.114 & 70.145 \\
\hline Comp. 65 & & & & & & & 8.367 & 7.743 & 66.922 \\
\hline Comp. 66 & & & & & & & 8.42 & 7.614 & 59.461 \\
\hline Comp. 67 & & & & & & & 4.596 & 5.601 & 62.102 \\
\hline & $\mathrm{X}$ & R2 & R3 & R4 & R5 & R6 & & & \\
\hline Comp. 68 & $-\mathrm{CH}_{3}$ & $-\mathrm{H}$ & $-\mathrm{OCH}_{3}$ & $-\mathrm{H}$ & $-\mathrm{OCH}_{3}$ & $-\mathrm{H}$ & 6.004 & 6.868 & 64.163 \\
\hline Comp. 69 & $-\mathrm{S}$ & $-\mathrm{H}$ & $-\mathrm{H}$ & $-\mathrm{OCH}_{3}$ & $-\mathrm{OCH}_{3}$ & $-\mathrm{H}$ & 6.357 & 6.140 & 60.714 \\
\hline Comp. 70 & $-\mathrm{S}$ & $-\mathrm{H}$ & $-\mathrm{OCH}_{3}$ & $-\mathrm{OCH}_{3}$ & $-\mathrm{OCH}_{3}$ & $-H$ & 5.921 & 5.363 & 45.562 \\
\hline Comp. 71 & $-\mathrm{S}$ & $-\mathrm{H}$ & $-\mathrm{H}$ & $-\mathrm{H}$ & $-\mathrm{OCH}_{3}$ & $-\mathrm{H}$ & 6.301 & 6.424 & 61.898 \\
\hline Comp. 72 & $-\mathrm{S}$ & $-\mathrm{H}$ & $-\mathrm{H}$ & $-\mathrm{Cl}$ & $-\mathrm{H}$ & $-H$ & 6.229 & 7.667 & 57.005 \\
\hline Comp. 73 & $-S$ & $-\mathrm{OCH}_{3}$ & $-\mathrm{H}$ & $-\mathrm{H}$ & $-\mathrm{OCH}_{3}$ & $-\mathrm{H}$ & 5.602 & 5.416 & 55.779 \\
\hline Comp. 74 & $-S$ & $-\mathrm{H}$ & $-\mathrm{H}$ & $\begin{array}{l}-\mathrm{H} \\
-1-\end{array}$ & $-\mathrm{Cl}$ & $-H$ & 6.377 & 6.479 & 55.430 \\
\hline Comp. 75 & $-S$ & & & $\begin{array}{c}\text { Napht } \\
\text { hyl }\end{array}$ & & & 6.357 & 6.103 & 40.676 \\
\hline Comp. 76 & $-\mathrm{CH}_{3}$ & $-\mathrm{OCH}_{3}$ & $-\mathrm{H}$ & $-\mathrm{H}$ & $-\mathrm{OCH}_{3}$ & $-\mathrm{H}$ & 5.569 & 6.322 & 61.723 \\
\hline Comp. 77 & $-S$ & $-\mathrm{H}$ & $-\mathrm{H}$ & $-\mathrm{H}$ & $-\mathrm{CH}_{3}$ & $-\mathrm{H}$ & 6.071 & 7.095 & 60.090 \\
\hline
\end{tabular}




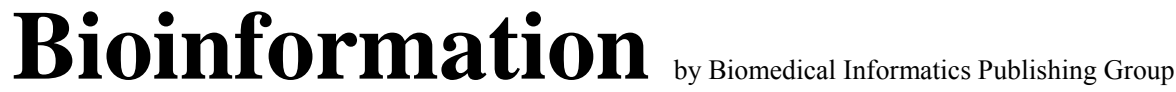<smiles>[R6]c1ccc([R6])c(NCc2cnc3nc(N)nc(N)c3c2C)c1</smiles>

DMDP derivatives in the series involving substitutions at the $\mathrm{R} 2$ and $\mathrm{R} 5$ positions.

R2

$-\mathrm{O}\left(\mathrm{CH}_{2}\right)_{2} \mathrm{CH}_{3}$

R5

Comp.78

Table 1: DMDP derivatives with modifications and Experimental activities and Predicted activities with DOCKSCORE. *activity for compounds was not predicted as they are found as outliers. 